\title{
Assessment of Cultural Practices That Hinder Transition of Learners with Special Needs in Education from Home to Pre-Primary Schools in Narok County, Kenya
}

\author{
Shinali Maryconsolata \\ School of Education, Maasai Mara University, Narok, KENYA
}

\begin{abstract}
The study intends to look at the cultural practices that hinder the transition of learners with special needs in education from home to pre-primary schools in Narok County, Kenya. The main objective of this study is to examine the cultural practices that hinder smooth transition of learners into pre-primary schools from their homes. The study will be supported by the Transition theory which posits that early childhood development is a natural and a universal process of progress transformation or stage transformation in children's moral, socio-emotional, mental/ cognitive and physical competencies and supports Piaget's theory that learners learn through interactions with their surrounding culture. The target population of the study will comprise of 53 schools, 53 head teachers, 53 teachers and 650 pupils and 2 Educational Assessment and Resource Center officers in Narok County. Simple random sampling will be used to select the schools, while the head teachers, teachers and pupils will be selected using purposive sampling as well as the EARC officers. The sample size will comprise of 15 schools, 15 head teachers, 15 teachers and 243 pupils. The study will use a descriptive survey design combining both qualitative and quantitative data collection techniques. The instruments will include questionnaires, structured interview schedules and observation checklists. The instruments will be pre-tested for validity and reliability in Bomet County Split-half technique will be used to assess the instruments' reliability while validity will be determined after it has been read through with the representative respondents. Purposive sampling will be used to select the pre-primary schools, learners, pre-primary teachers and the head teachers. Convenience sampling will be used to select the parents. The target population will be respondents from centers selected for the study. Data will be coded and analyzed by use of measures of central tendency encompassing mean, mode and percentages. The data will be analyzed and presented in tabular and graphical form. The study may be of significance to the EARC officers, head teachers, pre-primary teachers, parents and the policy makers at the ministry of Education, science and technology.
\end{abstract}

Keywords: Cultural practices, Transition, Pre-primary, Special needs, Early childhood education, EARC Officers DOI: $10.7176 / \mathrm{JEP} / 11-21-03$

Publication date:July $31^{\text {st }} 2020$

\section{CHAPTER ONE}

\subsection{INTRODUCTION}

Transition is a process of moving from one state to another. It can mean a change in location, curriculum and philosophy (Margretts, 1999). A person, be it a child or an adult may experience informal transitions each day as they move from one domain of their life to another for instance transition from home to hospital. Major transitions are often turning points that change a person's life and role, their behavior and what others expect of them. Normally, there is more or less preparation for such major transition. In Western industrialized countries, learners' move from a 'prior to school' setting such as childcare, a play group or a kindergarten to a school setting is often referred to as learners' transition to school. This involves changes for the child, their family and for the educators in the child's life. According to the center for equity and innovation in early childhood (2008), transition to school is often regarded as involving policy makers and the broader community who have an interest in how learners should experience the move to compulsory schooling, what schooling should produce and what it means to be a child who must attend school, perform the associated activities and also be able to meet the associated expectations of others.

In modern times, increasing attention has been given to the question of what preparation is needed by a child, family, the school they are going to attend and the wider community to ensure that a child's transition to school is a positive and successful experience. Studies in different countries e.g. Australia, Canada, New Zealand, Finland, Singapore and Germany show that starting school is a significant moment for learners and their families, irrespective of the age of which the child starts school (CEIEC,2008). A study of early childhood education and care across 38 countries showed that strong investment in Universal early childhood education and care improves learners' long-term educational outcomes.

Researchers in the U.S.A have found that a successful transition from pre-primary to the preparatory years of formal schooling has a long lasting educational and social benefit. These findings are supported by the findings of the Effective provision of Pre-school Education (EPPE) project a major European longitudinal study. EPPE studied 
the effects of pre-school provision on intellectual and social/behavioral development of 3,000 learners aged between 3 and 7 years old from different social backgrounds in the U.K The results were that quality early childhood settings that the learners attended had positive effects on their development during their performance in standardized tests of reading and mathematics in their first years of school. Transition from early childhood centers to primary school is the most significant one and has raised many interesting issues which have contributed to the debate regarding the provision of early childhood education. It is imperative that learners attend some form of preschool before enrolling in the primary school.

In order for transition to be successful, the parents have to play a key role. Early childhood centers which are center- based programmes for learners aged 3 years and above require pedagogies and curricula that takes into account the specificity of learners' development and any special needs they may have and the social context within which they live (Wetterberg, 2007).

Transition of learners with special needs in education from home to school is influenced by three dimensions which include socio-cultural, economic and historical factors, the provision of early Childhood Programmes and learning vary widely in low- and middle-income countries. This diversity in the provision of early childhood Development programmes is linked with the economic investment of the country. The cultural traditions of sending young learners to a pre-school and also the national policies support ECDE (UNICEF, 2011). Segregation of learners with special needs from other learners right from home to school impacts negatively on the learners. This may lead to missing out on learning opportunities for them (UNICEF, 2011).

According to Bruns, D.A and Towler S.A (2001), families of young learners with disabilities encounter many transitions with each presenting a variety of challenges as well as a set of common experience. Hains, Rosenkoetter and Fowler, (1991) asserts that the change from early intervention to pre-school services is often met with feelings of stress and anxiety as families adjust expectations learners change service delivery systems and adopts to new instructional procedures in the recent past, transition has received increased attention conceptually and empirically. General recommendations are recommended (Hains and Fowler, 1994). All guidelines emphasize family involvement, child preparation for new environment, information exchange between service provider, continuity between settings and compliance with respective regions or countries. Efforts have been undertaken in recent years to translate these recommendations into practices for young learners with disabilities and their families.

Lynch and Hanson (1992) emphasize the importance of respecting and incorporating cultural difference into culturally appropriate services. This can only be achievable if families' service providers and administrators come to a common understanding of how best to meet an individual family's needs during times of transition.

\subsection{Statement of the problem}

The role of families in transition of learners with special needs must be acknowledged and considered. This is so since the families are the learners' first and most important source of continuity. The needs of the families of learners with disabilities present unique as well as shared differences in relation to smooth transition. This is accelerated by the beliefs and taboos associated culturally with learners who have disabilities. Lynch and Hanson (1992) emphasize the importance of respecting and incorporating cultural practices and differences into culturally appropriate services. The tremendous decrease in the number of learners with special needs in education in schools in Africa has become a major issue and concern. Diverse factors contribute to the discrepancies one of them being traditional beliefs and stereotype cultural inclinations associated with disability. Learners living with disabilities in Kenya like in most developing countries are a marginalized population and face problems as a result of their disability. In most cases, they have no access to education, health, employment or rehabilitation. The majority of them experience hardships as a result of inbuilt social cultural and economic prejudices, stigmatization and more often than not, abuse and violence. A child who has disabilities is less likely than other learners to attend school and even less likely to go beyond primary schooling. Earlier studies have failed in articulating in specific terms how cultural practices have been that hinder a smooth transition of learners with special needs in education from home to Pre-primary schools. This has compelled the researcher to critically examine the cultural practices that come in the way of a smooth transition of learners with special needs in education to join Pre-primary schools in Narok County, Kenya.

\subsection{Purpose of the study}

The study intends to assess the cultural practices that hinder transition of learners with special needs in education from home to pre-primary schools in Narok County, Kenya.

\subsection{Objectives}

The study will be guided by the following objectives: -

1. To establish the influence of female genital mutilation on transition of learners with special needs in education from home to Pre-primary schools in Narok County.

2. To assess the influence of pastoralism on transition of children with special needs in education from home 
to Pre-primary schools in Narok County.

3. To examine the influence of parental involvement on transition of children with special needs in education from home to Pre-primary schools in Narok County.

\subsection{Significance of the study}

The study will contain information on the cultural practices that hinder the transition of learners with special needs in education into pre-primary schools in Narok County, Kenya. This study will acknowledge the learners who have disabilities in the county and will enable them have positive attitudes towards education. Parents may benefit from the study on disabilities and inculcate a positive attitude in their learners to join pre-primary schools. The local administration may be enlightened on the need to advocate for learners with special needs to transit to Preprimary schools. The Ministry of Education as policy makers may also benefit from the study as they will be able to put in place appropriate strategies to be used during the transition of learners with disabilities into ECDE centers. The study may be valuable to Non-Governmental organizations, sponsors and the community at large in facilitating a smooth transition of the learners with special needs into Pre-primary schools.

\subsection{Assumption of the study}

1. That there are learners with special needs in education in Narok County.

2. That all the respondents will give genuine, truthful and honest responses to the questionnaires and interviews.

3. That most people in Narok County are aware of children's right to education.

\subsection{Theoretical Framework}

Transition Theory which was postulated by Elder (1994) will be most appropriate for the study. This theory is anchored on the premise that the conceptualization of the term transition is almost perpetually underpinned by the theories about child development, especially the development psychology. According to Elder (1994), the development theories are necessarily engaged with the concept of transition, though not explicitly; all about it is the process of human beings' growth, transformation and change. In other words, transition theory is closely related to the ecological approach to human development.

The model understands human development as a multi-level phenomenon, comprising structured pathways through social institutions and organizations to the social trajectories of individuals. Elder (1994) posits that early childhood development is a natural and a universal process of progress transformation or stage transformation in children's moral, socio-emotional, mental/ cognitive and physical competencies. In the context of this study, the implication of viewing child development as a series of psychological progressive process of transformation, from one stage to another, such as from infancy to maturity, is that these stages/process is a crucial point of reference while discussing transition of learners from pre-primary to grade one in primary school or else from informal curriculum to more formal. Cognizant of the views of Vygotsky (1978), Elder (1994) stresses on activity rather than the individual. Elder (1994) indicates that children's environment, whether in the home setting or pre-primary, all the aspects of development are shaped by a multiplicity of dynamics inherent in such environments. This implies that, for any meaningful transition of learners with special needs from home to pre-primary schools, indicators such as enrolment trends, unique needs, parental involvement are key to such transitions.

\subsection{Limitation of the study.}

There will be limitations in controlling the intervening variables especially in dealing with the health conditions of these learners with special needs. The head teachers and pre-school teachers have limited knowledge and experience in handling learners with special needs especially during the transition period. There is limited literature on learners with special needs. Some respondents may be unwilling to divulge the cultural practices of their communities in dealing with learners who have disabilities as it is a taboo subject to date. The findings of this study will not be generalized to other counties as it will be limited to the cultural practices and beliefs of the communities living in Narok County.

\section{CHAPTER TWO}

\subsection{LITERATURE REVIEW}

Culture is a way of life of a particular society. Cultural practices in references to early childhood education has affected the school enrolments making it dismal. Cultural practices have an impact on school age going children. The Maasai community has cultural norms that hinder the education of children with special need children as opposed to the UN convention of the right of children which was ratified by the government of Kenya in 1990 . This stipulated that a child with disability has the right to special care education and training to help him/her self. This is emphases in the children Act 2002. Maasai cultural norms see people or children with disabilities as a bad 
omen to the family and societies. This has led to expulsion and elimination in their families' homes. The survival of these children hangs on a thin line if intervention measures are not forthcoming. J. Balachhandes (2008) posits that world bank support for early childhood development online states that the differences in cultural and economic environment makes it next to impossible to prescribe any single programme model for feeder section like any childhood development and education. Ministry of education strategic plan (2006-2011) states that the provision of pre-primary education in Kenya is a joint effort between the households' communities and the government. Traditional beliefs postulate that educating girls is a waste of time and money as they will eventually get married and that education benefits the families they will be married to. According to UNICEF (2003) states that every girl should have a right to education and this was supported by the child Act (2002) where the fundamental rights to education were being ratified so that every child should get access to quality education. Harmful cultural practice and attitudes inflicts physical and psychological damage to the children for instance initiation rituals and early marriages. The cultural practices have hindered promotion of gender equality and empowerment of women which is against achieving the second millennium goal that talks about the distribution of power and roles in society.

\section{CHAPTER THREE \\ RESEARCH DESIGN AND METHODOLOGY}

\subsection{Introduction}

In this chapter, there will be a presentation on the procedures that will be used to conduct the study, focusing on research design, target population, sample and sampling procedures, research instruments and data collection and analysis.

\subsection{Research design}

The research design is the basic plan for a piece of empirical research, it includes main ideas such as strategy sample and the tools and procedures to be used for collecting and analyzing empirical data (Punch, 2000). The role of research design is to connect the questions to the data. Sitting between the two is the design which shows how the research questions will be connected to the data and the tools and procedures to use in answering them. The study will employ a descriptive survey research design. According to Orodho (2002), descriptive survey research design is used in preliminary and exploratory studies to allow researchers to gather information, summarize present and interpret for the purpose of clarification the design entails employing both quantitative and qualitative approaches.

A descriptive research determines and reports the way things are (Mugenda and Mugenda, 1999). Borg and Gall (1989) asserted that descriptive survey research is intended to produce statistical information about aspects of education that interest policy makers and educators.

Since the researcher intends to collect data and report the way things are without manipulating any variable, the study fitted within the provision of descriptive survey research design.

\subsection{Area of study}

The study will be carried out in Pre-primary schools in Narok County, Kenya.

\subsection{Target Population}

Target population is defined as members of a real or hypothetical set of people, events or objects to which a researcher wishes to generalize the results of the research study. (Charles and Mertler, 2002). Population is the entire group of individuals to be studied in a given study area.

The target population of the study will comprise of 53 schools, 53 head teachers, 53 teachers and 650 pupils and 2 EARC officers in Narok County. The study will consider this group of respondents as they are in direct contact with the learners at home and in ECDE centres. The respondents earmarked are in a position to provide appropriate data on the cultural practices that hinder transition of learners with special needs in education at home to ECDE centres.

\subsection{Sample and sampling techniques}

Sampling techniques means selecting a given number of subjects from a defined population as representative of that population. Any statement made about the sample should be true of the population (Orodho, 2002).

However, it is agreed that the larger the sample, the smaller the sample error. Gay, (1992) recommends that when the target population is small or less than 1000 members, a minimum sample of $20 \%$ is adequate for educational research. Simple random sampling will be used to select the schools, while the head teachers, teachers and pupils will be selected using purposive sampling as well as the EARC officers. The sample size will comprise of 16 schools, 16 head teachers, 16 teachers and 243 pupils 


\subsection{Research instruments.}

This study will mainly use questionnaires and interview schedules and also observation checklist.

\subsection{Reliability}

Mugenda and Mugenda (2003) define reliability as a measure of the degree to which a research instrument yields consistent results of the data after repeated that.

A pilot study will be carried out in order to enable the researcher to assess the clarity of the questionnaire items so that those items found to be inadequate or not clear will be modified to improve the quality of the research instrument thus increase its reliability.

\subsection{Validity}

Validity refers to the accuracy and meaningfulness of inferences which are based on the research results as cited by (Mugenda and Mugenda, 1999). Validity is the degree to which results obtained from the analysis of the data representing the phenomena under the study. Borg and Gall (1989) states that validity is the degree to which a test measures what its purpose measures. All assessments of validity are subjective opinions based on the judgment of the researcher (Wiermai, 1995). The pilot study assists in improving the face validity of the instruments. Content validity of an instrument is improved through the experts' judgment. This means that the researcher will seek assistance from the superior and lecturer who are the experts to help improve content validity of the instrument.

\subsection{Data collection procedure}

The researcher will send research assistants to interview the EARC officers, parents and the local administrators. They will also distribute questionnaires to the pre-school teachers to fill. The researcher will give the questionnaires to the EARC officers and local administrators. Assurance will be given to all the respondents and strict confidentiality will be maintained.

\subsection{Methods of data analysis}

The study will generate both qualitative and quantitative data. Data will be analyzed qualitatively using contents analysis based on analysis of meanings and implications that will emanate from respondents' information and documents data. According to Gay (2004), qualitative data provides rich descriptions and explanations that demonstrate the chronological flows of events as well as often leading to chance findings.

Qualitative data will be analyzed using various statistics including measures of central tendency and dissension. Simple descriptive statistics will be employed to analyze quantitative data. The statistics will include frequency count, means and percentages. Open ended questions will be analyzed thematically. The results of data analysis will be presented using frequencies, distribution tables and bar graphs.

\section{REFERENCES}

Borg, W. R and Galm, M. D (1989). Education Research; An introduction $4^{\text {th }}$ edition, New York, London Bruns, D. A and fowler, S. A (2001). Transition is more than a change in services; The need for a multicultural perspective. New York Teachers college press.

Balachandr, j. (2008), world Bank support for ECDE. USA [5].

Fowler, S. A and Ostrosky, m (1994). Transition to and from preschool in early childhood special education P. L. saffod, B. Spodek, and ON saracho (EDs)New York teacher's college press.

Fowler, S. A, Schwartzman Atwater. (1991). Perspectives on the transition from preschool to kindergarten for learners with disabilities and their families

Hains, A.H, Fowler; and chandler, L.k (1988). Planning school transition family and professional collaboration: journal of the division for early childhood.

lynch, E. W; and Hanson, M. J (1992). Steps in the right direction; implications for interventionists. Baltimore Brooks.

Margetts, K (1999). Transition to school; looking forward. Paper presented at the AECA conference Darwin, July 14-17 1999.Retuered from the worldwide web at http:/www.aeca.org.au/dar confmarg.html.

Mugenda, O.and Mugenda A (1999). Research methods, qualitative and quantitative approaches. Nairobi acts press.

Orodho, J. A (2002). Techniques of writing proposal and reports in education and social science Nairobi Masola publishers.

Gray. R (1992). Educational research, competences for analysis and application. Ohio; Charles E. Merrill publication. 